\title{
Individuality and Diversity among Undergraduates' Academic Information Behaviors: An Exploratory Study
}

\author{
Diane Mizrachi*
}

\begin{tabular}{l} 
ARTICLE INFO \\
\hline Article history: \\
Received 13 August 2013 \\
Revised 19 November 2013 \\
Accepted 29 November 2013
\end{tabular}

Keywords:

Information behaviors,

personal information

management,

college students

\begin{abstract}
The purpose of this study is to explore the information management behaviors of undergraduate students in their dormitory rooms, using Personal Information Management (PIM) as the theoretical framework. Ethnographic methods were applied to study how students devise their own systems combining digital and traditional tools to collect, create, manipulate, organize, and manage the information they need to fulfill their roles as university students. Results show a broad diversity of behaviors influenced more by individual learning styles and preferences than high-tech gadgetry. It is proposed that just as every individual has unique learning styles and preferences, so too do we have individual information styles, and we apply our tools and gadgets in our own ways to best accommodate our own styles.
\end{abstract}

\section{Introduction}

This study investigates how college students organize and manage their personal academic information - the information they create, collect and use to complete their academic tasks and fulfill their roles as students. It is based on research in Personal Information Management (PIM), a sub-field of Human-Computer Behavior that "refers to both the practice and study of the activities a person performs in order to acquire or create, store, organize, maintain, retrieve, use, and distribute the information needed to complete tasks $\cdots$ and fulfill various roles and responsibilities," (Jones, 2006, p. 453). Previous studies of PIM however, overwhelmingly focus on adult professionals in their places of employment with the ultimate goal of designing applications and gadgets to aid and improve management tasks. College students are easily stereotyped by the media and institutions of higher education as 'digital natives' - having grown up in a digital world they prefer to work, play and study online using the latest electronic gadget or application. Assumptions about their behaviors, based on mass surveys, look at generalities but do not provide perspectives into the numerous individual nuances and exceptions. Technological and pedagogical policy decisions based on generalities and stereotypes miss important aspects of students' information behaviors and preferences, thus forming barriers to their learning potentials.

* University of California Los Angeles (mizrachi@library.ucla.edu) International Journal of Knowledge Content Development \& Technology, 3(2): 29-42, 2013. http://dx.doi.org/10.5865/IJKCT.2013.3.2.029 
Ethnographic methods were employed to investigate the information organization and management behaviors of undergraduates in their campus residential rooms at a large research university. The wide range of behavioral preferences they display when using their laptops, software, social networking sites, academic reading formats, cell-phones, and note-taking tools for academic tasks are described and analyzed. Diversity of practices in how students employ and apply these tools to manipulate course materials - an essential component of their learning process, and the ancillary strategies they use to help them organize their information are also discussed. The proposition is made that just as every individual has unique learning styles and preferences, so too do we have individual information styles, and we apply our tools and gadgets in our own ways to best accommodate our own styles. Findings from this study further our understanding of college students' information behaviors, and will be of interest to practitioners and scholars in the fields of higher education, library and information science, and information technology.

\section{Review of the literature}

College students are frequent subjects of studies of information seeking behavior, Internet-use, library behavior, research behavior, information literacy, and technology behaviors over the last several decades (see e.g. Mellon, 1986; Kuhlthau, 1991; Valentine, 1993; Pena-Shaff, Martin, \& Gay, 2001; Agosto, 2002; Seamans, 2002; Whitmire, 2004; Weiler, 2005; McMillan \& Morrison, 2006; Walters, 2009; Paretta \& Catalano, 2013). Several institutions support and engage in research into the academic, technological, and general lifestyles of these students.1) But for all that has been studied and written about college students, it is a population whose organizational and management behaviors with their academic information has just begun to be explored.

Anthropologist Nancy Foster was hired by librarians at the University of Rochester to lead an ethnographic study of how students at their institution actually go about researching and writing their academic papers with the goal of enabling library staff to adjust their services and practices accordingly. Teams of librarians and library staff conducted the research and wrote up their findings in a series of descriptive chapters (Foster \& Gibbons, 2007). More recently, a team of anthropologists conducted the ERIAL project (Ethnographic Research in Illinois Academic Libraries) which explores how hundreds of students in five different Midwestern universities conduct research for classroom assignments, expectations held by faculty and librarians for this research, and the spaces and tools students use for their academic tasks (Duke \& Asher, 2012).

Thomas Malone (1983) is recognized among PIM scholars as conducting the groundbreaking study of the organization of people's desks and offices at their place of employment. "I use the term desk organization loosely to include not only the desks, but also the tables, shelves, file cabinets, and other information repositories in people's offices," (p. 100). From interviews with professionals and clerical office workers he maps out and analyzes their personal organizational strategies and

1) For example see: http://www.gseis.ucla.edu/heri/herisurveys.php; http://nsse.iub.edu/index.cfm; http://cseq.iub.edu/index.cfm and http://monitoringthefuture.org/ 
D. Mizrachi
International Journal of Knowledge Content Development \& Technology Vol.3, No.2, 29-42 (December, 2013)

spaces, seeking to aid the design of electronic information systems. Today, William Jones at the University of Washington is the most prominent scholar of PIM. He manages the 'Keeping Found Things Found' project, which is dedicated to the study and practical applications of PIM (Jones, 2008; Jones, 2012).

Researchers in Israel explored how university students organize their personal information spaces in an online environment. Data mining techniques were used to identify personal information space organization strategies on personal Web space allocated by their university to a mix of over two thousand graduate and undergraduate students (Hardof-Jaffe, Hershkovitz, Abu-Kishk, Bergman, \& Nachmias, 2009; Hardof-Jaffe \& Nachmias, 2013). The researchers recognize the influence of PIM on the learning process and emphasize the need to study further the PIM characteristics in learning contexts. Personal Learning Environments (PLEs) is "a newcomer in the field of [information and communication technology] (ICT)" in which "[s]tudents are placed in a central role as designers of their own learning environments $\cdots$ typically described as a collection of different ICT tools and software ..." (Valtonen, Hacklin, Dillon, Vesisenaho, Kukkonen, \& Hietanen, 2012), These studies and concepts have similar goals to this current study - i.e. discovering students' personal information management strategies, but they examine only online environments and electronic media and tools. The current study takes a more holistic approach by examining students' management behaviors and integration of both digital and print formats.

\section{Methods}

This study uses three data gathering methods: guided tours of the students' academic environments supported by video and photographic inventories, semi-structured interviews, and students' free-write descriptions of their environment and behaviors. All participants are undergraduates living in on on-campus housing at the University of California Los Angeles (UCLA), a public research institution with over 26,000 undergraduates, of whom approximately 9,000 live in on-campus housing. Administrators in UCLA's Office of Residential Life (ORL) posted recruitment fliers throughout the complex, sent email appeals to student resident advisors and staff, and announced calls for participants at various staff meetings in October 2009. In response to these fliers, students initiated email contact with the researcher to schedule interview appointments (For more details on this study see: Mizrachi, D., 2010; Mizrachi, D., 2011).

Forty-one students were interviewed in their rooms. Participants consisted of 28 females (68\%) and 13 males (32\%) between the ages of 18-22 years, 31 of whom were in their first or second year of study. Not all students had yet declared a major, but based on their stated interests it is possible to assume that twenty-two of the forty-one participants showed an orientation towards the sciences, and the others interested in the social sciences or arts and humanities. Many of these students are still exploring their interests, still taking general education (GE) courses, and may change their majors at least once or twice before graduating. They may have an academic direction, but most are not yet immersed in a specific disciplinary culture like graduate students and scholars. Each interview was scheduled for an hour, but averaged around forty minutes. Several students commented 
on how much fun the interview was, how interesting the topic was, or that they had never thought of their behaviors in such a way. In general, the students enjoyed the opportunity to share and talk about themselves. Perhaps on such a large and sometimes impersonal campus, it helped them express their individuality and feel more like a contributing member of the community.

Students were first asked to show the researcher their academic 'stuff,' both digital and physical, and discuss where they keep use and keep it, what they use, and how they organize it. This guided tour was video and audio recorded, and particular features were photographed depending on their uniqueness, typicality, or centrality to the student's behaviors. Semi-structured interviews following a basic protocol explored behaviors and attitudes further, however the researcher allowed each students to lead the conversation as much as possible. More specific probing questions were asked as relevant. Finally, students were handed a piece of paper with the prompt "How I manage the information I need for school in my residence hall room," and asked to free-write their own answers in up to ten minutes. Responses were recorded in short essays, outlines or bullet points, and sketches. Using three data gathering methods elicited a more complete picture of the individual's management behaviors, and strengthened the data through the triangulation of responses.

\section{Findings}

\subsection{Application and use of academic information tools}

\subsubsection{Computers}

All of the students in this study own a laptop, which they consider the key element in their life as a student. Only one student uses a desktop computer in her room, but also uses her laptop for mobile computing needs. Four other students use two forms of computers - three keep their laptops on their desk in their rooms and take a 'mini' laptop for mobile computing, and one uses both her Mac and Windows-based laptops. It must be noted that interviews were conducted before the public debut of the i-pad and similar tools.

When asked whether they bring their laptops to class with them on a regular basis students displayed a range of behaviors and attitudes. Twenty-three of the forty-one participants say they do not bring their computer to class and prefer to leave it in their room during the day. Six reasons for this behavior emerge: security (fear of theft or damage), discouragement from professors, technical issues, size (too heavy and bulky), too distracting, and individual learning styles and preferences (they prefer to handwrite, or claim to learn better when writing). About the latter two reasons, students state:

Distractions:

- "Usually [the laptop] gets in the way. You $\cdots$ go bug off on Facebook."

- "I find it distracting. A lot of people go on Facebook and stuff in class."

- "With a laptop I'm usually on Facebook or on the Internet or something like that."

- [In seminar class discussions] "having a laptop up in front of your face is kind of distracting." 
D. Mizrachi
International Journal of Knowledge Content Development \& Technology Vol.3, No.2, 29-42 (December, 2013)

Individual learning styles

- "I just feel that when you're writing notes, even if you go off and doodle, a lot of times when you look at the doodle, you'll re-reference what you learned in class, whereas when you're typing, you're kind of just mindlessly typing. You're not really looking at what you just typed … I feel I make a better connection writing down the material and I actually like looking at it [more] than a computer's interface."

- "I learn better when I write things down and that keeps me more on task $\cdots$ It's a better way for me to organize my information."

- "When I'm [taking notes by hand] I'm trying to understand what I am writing down."

- "I think I get more information when I'm writing the notes myself. When I type them up it just kind of looks like a document that the teachers are giving me and I don't really pay much attention to it $\cdots$ I think writing is so much better $\cdots$ I just like writing better.”

Several participants report that they bring their laptops to certain classes depending on the context and type of material being presented. Most commonly, they bring computers to large lecture classes in the social sciences and humanities, but don't find them practical for other kinds of classes such as small discussion sections, seminars, foreign languages, science, and mathematics classes. Because many forms of information in the latter disciplines are represented in formulas, graphs, symbols, or other graphic formats that cannot yet be represented easily on a laptop, students prefer to take notes by hand in notebooks, course readers, or on pre-printed PowerPoint slides from their course webpage.

\subsubsection{Course webpages}

All students access their course webpages regularly for communications, announcements, homework assignments, readings, lecture notes and PowerPoint slides. Five of the students have used the online discussion forums feature, usually because they were required by the instructor. Attitudes about the experience were mixed. Several students report accessing audiocasts and podcasts of class lectures through their course webpages as 'make-up' or supplementary sessions. Students most commonly use email for communications with their professors and institutional needs, but prefer texting, online chat, instant messaging, social network sites, and phone calls for communications with their friends and peers.

\subsection{Reading format preferences}

Thirty of the forty-one students in this study proclaim a preference for reading academic material in print rather than online if given a choice, but admitted that the convenience and monetary savings of online access often impacts their actual behavioral decisions. As one student noted:

"In an ideal world I would prefer to have [readings in print] because it is definitely easier to have

it in front of you because you can highlight it and stuff. But I definitely prefer when [classes] have 
34 International Journal of Knowledge Content Development \& Technology Vol.3, No.2, 29-42 (December, 2013)

online readings because you don't have to buy a text book. And it's more convenient, you can just click on it. Yeah, it saves you money and then also it's nice when you don't have papers all over the place $\cdots$ But I definitely do get more out of [the reading] when it's on paper"

Students' reasons for preferring print to online format include eyestrain from computer screens, too many distractions online or that print format is more portable and easier to use. But the single most common reason that students prefer reading their academic material in print for is because they can interact with the text and absorb the information much better. Highlighting and taking notes on the print copy is important to them, and many state that being physically involved with the reading is how they learn best: "When you have a paper copy in front of you, you can mark it, annotate it. You can actively read with it."

Even though the majority of students express a preference for print, many actually do most of their reading online. They don't want to waste paper, don't have their own printer, paper and/or ink are expensive, or it's just easier for them to read online: "I would prefer to read it in print but I read online 'cause I don't want to buy ink." Others told me it depends on the content, context, and length of the reading. "If it's a short article I will read it online"; "It depends how long the document is and for what purpose I'm reading it"; "It depends on the situation. If it's a long article, I prefer to read things on paper so I can highlight and take notes, but if it's short and not that important I'll read it on the computer."

\subsection{Facebook}

All students in this study have a Facebook account, and they use it primarily for social networking purposes. Over thirty of them recall using Facebook on at least one occasion for an academic purpose during their undergraduate years. Common uses are posting or chatting about homework questions with classmate 'friends,' and organizing study groups: "I create an event then invite people." One worked on a group project with her classmates through Facebook. They gathered together in the same room, each with their own laptop, and posted their working document into a single Facebook thread. "We thought it more efficient for our lab report. Each worked on a different section. This way we could talk about it, share ideas easily, but still work on our own parts. It was easier than email." One student distributed a survey as part of a class assignment to his friends on his Facebook account. And because some professors speak very fast and erase their notes and illustrations in their lectures before she can copy all of them down, another student said she often takes pictures of the classroom whiteboard with her camera and then posts the photos on Facebook to share with her classmate 'friends.' No student reported 'friending' a professor. One participant acknowledges wasting a lot of time on Facebook so gets her (physical) friends to change her account password during exams and finals so that she cannot access it.

\subsection{Notetaking behaviors}

Thirty-six students in this study use spiral notebooks for recording their handwritten notes in at 
D. Mizrachi
International Journal of Knowledge Content Development \& Technology Vol.3, No.2, 29-42 (December, 2013) 35

least some of their classes. Others use loose leaf pages or scratch paper which they later copy into word documents or by longhand into another notebook for review, reinforcement, better organization, or to make them neater and easier for review later on. Students in science classes such as chemistry and biology must purchase course readers, and this is where they record their main class notes. Often instructors post PowerPoint slides or lecture notes ahead of time on their course webpage, which students then print out and use for note-taking. A few students will pull them up online in class and take their notes digitally.

\subsubsection{Manipulation of course materials for learning purposes}

A primary task of the students is manipulating and using the information they have gathered from their class meetings in a manner that will best help them learn and understand the information. They must effectively integrate it with other course material and organize it all in a system which allows easy access for quick reference and referral. Manipulation occurs when students interact with the information, and can involve making alterations to its appearance, format or location. Cognitive and physical interactions with academic information include reviewing, reading, writing, copying, sorting, piling, filing, discarding, deleting, archiving, placing (purposefully setting information within the environment for accessibility, visibility, and reminding), shifting (purposefully moving information carriers from one side of the desk to another), and prioritizing (by urgency, or importance). These actions occur throughout the various stages of the students' work flow, not necessarily in a linear manner, and depend upon temporal factors as well as individual personalities and habits. Students develop and employ manipulation strategies to assist their cognitive absorption and understanding of the information. Though some actions and strategies can be applied in both print and online formats, students in this study use a greater variety of strategies when they interact with their paper-based material.

Information manipulation strategies vary greatly according to individual personalities, learning styles, and previous experiences from which they discovered and developed behaviors that seem to effectively meet their needs. Beginning the cognitive process of learning by first organizing their information helps students decide upon the best strategies for each particular situation: "First I categorize the materials needed and make sure I'm not missing anything. Then I formulate a studying pattern." Transcribing notes and reviewing audiocasts and podcasts helps refresh the material and solving assigned or practice problems helps strengthen understanding. Learning the material well also demands some rote memorization as well as the ability to separate main themes from supporting themes, and subsequent categorization of the information under review. Students commonly use thick highlighting pens to emphasize main points and themes as they read or review, and some have developed elaborate color schemes to help them distinguish different types of information within their notes and readings.

Index cards are frequently used as study aids for classes and material that demand memorization such as biology, languages, psychology, math and chemistry. Students in chemistry classes purchase molecule model kits which helps them visualize the structures of important molecules. Looking like tinker toys, they are assembled according to the specific characteristics of each molecule, a 
36 International Journal of Knowledge Content Development \& Technology Vol.3, No.2, 29-42 (December, 2013)

strategy involving kinesthetic learning.

After completing a course of study, some students retain only their digital materials, but most usually retain a selection of their physical books, readings, notes and projects, and a few claim to keep everything. Reasons for retention are because the material or topic is especially interesting, for possible reference in the future, or to share or pass material on to others. Often the students want to keep an outstanding paper or other project, or they might retain material just for sentimental reasons. It is also not unusual for students retain course material from high school and even earlier.

\subsection{Ancillary strategies}

Ancillary strategies are purposeful actions which students use to support their information management and organizational goals, and to help them manage the information relevant to their tasks and roles as students. Three ancillary strategies were identified: planning, reminding, and noting. Planning is the formulation of a scheme or method to accomplish an academic task. It includes deconstructing a project or goal into smaller components and mini-goals, prioritizing those components, and scheduling them - meshing them into manageable timeframes by assigning dates and times. Reminding actions cause the student to remember or think of a specific task. Noting is the recording short information scraps. Noting actions may result in the creation of reminders, but their primary intention is to create a record for later referral or reference. For each of these strategies, students use enabling actions such as ordering, sorting, color coding, highlighting, jotting, listmaking, outlining, posting and placing. Various tools utilized for executing these actions include paper day-planners, paper and electronic calendars, paper and electronic Post $-\mathrm{its},{ }^{\mathrm{TM}}$ word documents, electronic spreadsheets, note-paper, scratch paper, memo and text functions on the phone, alarms, and whiteboards. Several students even write notes to themselves on their hands!

Students invest much time and thought developing and executing their ancillary strategies. One describes her paper day-planner as "my pride and joy $\cdots$ I plan basically everything that's going on, like any meetings, anything that's due, even lunches." Another summed up what several students expressed about their list-making behaviors: "I have to write everything down so I don't forget to do it. Lists are very helpful to me for clarity and as motivation to check something off the list. Knowing exactly what needs to get done and having a mental deadline helps me to stop stressing about work and focus. If anything, deadlines are what help me the most."

\section{Discussion}

This current study of undergraduates' information practices clearly shows that a broad spectrum of individual information behaviors and preferences exists among students. Individuality of adult personal information management (PIM) behaviors and practices is well documented in the PIM literature (Jones, 2008, p. 127, 124). It is unfortunate then, that the student demographic group is so easily stereotyped in popular media as well as by academic institutions. $R$ U Talking $2 \mathrm{Me}$ ? an article published in the July 2010 UCLA Magazine discusses the impact of new technologies 
on communication, culture and education. It begins: "In a world where it's obsolete to note that laptops are the new spiral-bound notebooks ..." (Hewitt, 2010). Findings from among the students in this study show that these types of assumptions are over generalized and unfair to this population. Individuality of behaviors among undergraduates should be as recognized and respected as it is among adults. Laptops have yet not replaced spiral notebooks for all notetaking purposes, for example, and preference for reading important academic material in print format is still found among most of the students. While some use their phones features or computer applications for noting important information and dates, many others prefer paper planners, sticky-notes, or even their hand! And high-tech behaviors and preferences are not necessarily consistent under varying contexts and circumstances even among the same individual. Some students for example take their computer everywhere with them, but are still highly dependent on a paper day-planner and take notes in spiral notebooks for certain classes.

Advances in technology will soon eliminate the size and technical issues that the students cite for not bringing laptops to class or using them for note-taking, and eventually the challenges of recording non-alphabetical information too. But they will not solve the challenge of keeping on focus and not diverting into digital distractions. Studies are showing that doodling on paper can aid a person's concentration in meetings and long lectures (e.g. Andrade, 2010), but going to Facebook and other online sites appears to be a different type of cognitive activity which distracts students and lessens their concentration and focus in class. One student takes her mini laptop to class regularly but the Internet has been disabled. For many, not bringing their computer to class is a conscious strategy to avoid the online temptations - a behavior reported in other studies of undergraduates as well (Foster \& Gibbons, 2007). As technology advances, will these preferences and behaviors evolve too, or is this a cognitive phenomenon hardwired into our brains? This is a question that cognitive and educational researchers and practitioners.

Studies are beginning to show a relationship between the type of reading format and the cognitive process of information absorption. Anne Mangen and her colleagues in Norway compared reading comprehension levels of high school students using print or electronic formats and found that "students who read texts in print scored significantly better on the reading comprehension test than students who read the texts digitally," (Mangen, Walgermo, \& Brønnick, 2013, p. 61). "There is a close relationship between the media we use to read - books or digital technology - and the way we read and think $\cdots$ Digital technology is often preferable for searching and scanning short snippets $\cdots$ slow reading of books is still essential for nurturing literacy and the capacity for extended linear thought" (Miedema, 2009, pp. 19-20). Nicholas Carr (2013, p. 4) points out "The physical presence of the printed pages, and the ability to flip back and forth through them, turns out to be important to the mind's ability to navigate written works, particularly lengthy and complicated ones." Several U.S. colleges recently ran pilot experiments in which academic readings were downloaded onto Kindle readers in order to explore how students compare online academic reading to traditional paper-based formats. The Chronicle of Higher Education reports "The Kindle project was expected to be a huge success, but the devices proved to be an unexpected flop" (Young, 2010). One Princeton student participant states: "I wasn't able to absorb the material as well as if I had hard copies of the readings, and I had to deal with a lot of technical inconveniences just from the design 
D. Mizrachi

38 International Journal of Knowledge Content Development \& Technology Vol.3, No.2, 29-42 (December, 2013)

of the Kindle" (Wonpyo, 2010). The behavior and comments of the students in this current study seems to indicate that, at least with the technology currently available, print works best for focused, interactive reading, but they feel a strong motivation to be economically and ecologically responsible. Other current studies and polls show a mix of reading preferences (e.g. Rainie et al., 2012). This question of reading formats is of major importance to librarians, educators, technical designers and cognitive researchers. Will digital eventually replace print? Will the cognitive process involved in deep reading and retention of information evolve so that the format from which it is read does not make a difference? Or will the adaption of digital reading fundamentally change our cognitive and learning processes - paralleling the cognitive changes that occurred when Western society moved from oral learning to literacy?

Barreau (2008) writes "Past studies suggest PIM behaviors are highly personal, idiosyncratic, and contextual and there is evidence that at least some behaviors persist over time" (p. 2). Educators are very familiar with theories of learning styles (individual approaches or ways of learning), and the need for varieties of pedagogical methods that address these differences in learning styles so that each individual can best fulfill their potential. It becomes apparent that there are individual information styles too. These appear to be based primarily in endogenous factors (personality, values, cognitive style, affections, etc.) amongst each individual, and may or may or may not be tied to learning styles. Attempting to implement institutional programs based on the assumption that all students need or even want to use the newest technology may prove unfair to those students whose information styles and preferences differ. The students in this study appear to give great thought to the tools they use for their information tasks. Even when they see their peers do similar information tasks differently, they express confidence that they are using the appropriate tool for them, and it feels presumptuous to try to convince students otherwise. Students who are pressured or socialized into adapting expected behaviors may never even have the opportunity to discover which methods work best for them, and this in itself may act as a barrier to fulfilling their learning potential.

The behavioral tendencies of the student participants here show a hybridity of high-tech and traditional information collections, formats, and tools rather than a reflexive rush towards total embracement of the newest gadgets and applications. All students use traditional information tools - books, notebooks, binders, paper and stationery in combination with higher tech tools like laptops and cell phones. Students' choice of tools and formats to use for their various tasks and under various circumstances appears to be driven by cognitive styles, learning styles, information styles, and personality traits. It is possible that digital native students, those who have grown up in a digital world, do not even recognize the distinction between the different formats as sharply as older digital immigrants do. Growing up in a digital world allows for an attitude that considers technical gadgets a natural part of life. They are simply part of a repository of 'stuff' the students use for many things including academics. Extensiveness of a student's array of 'stuff' may be constrained by outside factors like socio-economic status or cultural practices, but the variety of behaviors within those limitations are broad and reflect individual personalities, tastes and styles. 
D. Mizrachi

International Journal of Knowledge Content Development \& Technology Vol.3, No.2, 29-42 (December, 2013) 39

\section{Conclusion}

This study explores and describes the academic information organization and management behaviors of forty-one undergraduate students at one institution. It is evident that contrary to popular beliefs about the digital native generation, students are still very dependent on non-digital tools and formats, which they integrate into their personal academic information environments. Findings here mirror the array of information management behaviors found in other PIM studies, providing strong evidence for the proposition of personal information styles. Worthy of further exploration is the question of how individual information styles are related to learning styles. Bergman, Beyth-Marom and Nachmias (2003) state that PIM has been identified as "one of the central components of an individual's learning process." Deborah Barreau (2008) notes that novice scholars process information in their environments differently than experts and asks if we can "help novices to become experts by improving their personal information management skills." Hardof-Jaffe et al write that "PIM activities have an acute influence on the learning process, and particularly on university students who engage with many information items from various sources" (2009, p. 1). Some students in this study believe they improved their learning (as measured by a rise in their grade point average), by improving their information management behaviors. Is there a relationship between information management styles and GPAs? Can an index of information behavior styles be developed? Could it be mapped to existing learning style dimensions such as active/reflective, sensing/intuitive, visual/verbal, and sequential/global, and then be used to help students explore and develop behaviors that best suit their particular styles? These are questions we must continue to explore.

\section{References}

Agosto, D. (2002). Bounded rationality and satisficing in young people's Web-based decision making. Journal of the American Society for Information Science and Technology, 53(1), 16-27.

Barreau, D. (2008). From novice to expert: Personal information management in learning contexts. CHI 2008, Florence, Italy. Retrieved January 27, 2011, from http://pim2008.ethz.ch/papers/pim2008-barreau.pdf

Bergman, Beyth-Marom, \& Nachmias. (2003). The user-subjective approach to personal information management systems. Journal of the American Society for Information Science and Technology, 54(9), 872-878.

Carr, N. (2013, issue 004). Paper versus pixel: The science of reading shows that print and digital experiences are complementary. Nautilus Quarterly, Retrieved November 8, 2013 from http://nautil.us/issue/4/the-unlikely/paper-versus-pixel

Duke, L. M., \& Asher, A. D. (Ed.). (2012). College libraries and student culture: What we now know. Chicago, IL: American Library Association.

Foster, N.F., \& Gibbons, S. (eds.). (2007). Studying Students: The Undergraduate Research Project at the University of Rochester. Chicago. Association of College \& Research Libraries.

Hardof-Jaffe, S., Hershkovitz, A., Abu-Kishk, H., Bergman, O., \& Nachmias, R. (2009). Students' 
40 International Journal of Knowledge Content Development \& Technology Vol.3, No.2, 29-42 (December, 2013)

Organization Strategies of Personal. Journal Of Digital Information, 10(5). Retrieved January 27, 2011, from https://journals.tdl.org/jodi/article/view/438/541

Hardof-Jaffe, S., \& Nachmias, R. (2013). Students' personal information management, In Jan Herrington et al. (Eds), Proceedings of the World Conference on Educational Multimedia, Hypermedia and Telecommunications 2013 (pp. 820-828). Chesapeake, VA: AACE. Retrieved November 8, 2013 from http://www.editlib.org/p/112055.

Hewitt, A. (2010). R U Talking 2 Me? UCLA Magazine, July: 23-25, 48.

Jones, W. (2006). Personal Information Management. The Annual Review of Information Science and Technology, 41, 453-503.

Jones, W. (2008). Keeping found things found: The study and practice of personal information management. Burlington, MA: Morgan Kaufmann.

Jones, W. (2012). The futureof personal information management: Part I: Our information, always and forever. San Rafael, CA: Morgan \& Claypool.

Kuhlthau, C.C. (1991). Inside the Search Process: Information Seeking from the User's Perspective. Journal of the American Society for Information Science, 42(5), 361-371.

Malone, T.W. (1983). How Do People Organize their Desks? Implications for the Design of Office Information Systems. ACM Transactions on Office Information Systems, 1(1), 99-112.

Mangen, A., Walgermo, B. R., \& Brønnick, K. (2013). Reading linear texts on paper versus computer screen: Effects on reading comprehension. International Journal of Educational Research, 58, 61-68. Retrieved November 8, 2013 from http://dx.doi.org/10.1016/j.ijer.2012.12.002

McMillan, S. J., \& Morrison, M. (2006). Coming of age with the Internet: A qualitative exploration of how the Internet has become an integral part of young people's lives. New Media \& Society, 8(1), 73-95.

Mellon, C. (1986). Library anxiety: a grounded theory and its development. College \& Research Libraries, 47, 160-165.

Miedema, J. (2009). "Slow Reading." Duluth, MN: Litwin Books.

Mizrachi, D. (2010). Undergraduates' academic information and library behaviors: preliminary results. Reference services review, 38(4), 571-580.

Mizrachi, D. (2011). How do they manage it? An exploratory study of undergraduate students in their personal academic ecologies. Unpublished doctoral dissertation, University of California, Los Angeles.

Paretta, L., \& Catalano, A. (2013). What Students Really do in the Library: An Observational Study. The Reference Librarian, 54(2), 157-167.

Pena-Shaff, J., Martin, W., \& Gay, G. (2001). An epistemological framework for analyzing student interactions in computer-mediated communication environments. Journal of interactive learning research, 12(1), 41-68.

Raine, L., Zickuhr, K., Purcell, K., Madden, M., \& Brenner, J. (2012). The rise of e-reading. Retrieved from http://libraries.pewinternet.org/2012/04/04/the-rise-of-e-reading/ 16 July, 2012.

Seamans, N. H. (2002). Student perceptions of information literacy: insights for librarians. Reference Services Review, 30(2), 112-123.

Valentine, B. (2001). The legitimate effort in research papers: Student commitment versus faculty 
expectations. The Journal of Academic Librarianship, 27, 2(2001): 107-15.

Valtonen, T., Hacklin, S., Dillon, P., Vesisenaho, M., Kukkonen, J., \& Hietanen, A. (2012). Perspectives on personal learning environments held by vocational students. Computers \& Education, 58, 732-739. doi: 10.1016/j.compedu.2011.09.025.

Walters, W.H. (2009). Google Scholar Search Performance: Comparative Recall and Precision. portal: Libraries and the Academy, 9(1), 5-24.

Weiler, A. (2005). Information-seeking behavior in generation Y students: Motivation, critical thinking, and learning theory. Journal of Academic Librarianship, 31(1), 46-53.

Whitmire, E. (2004). The relationship between undergraduates' epistemological reflection, reflective judgment and their information seeking behavior. Information Processing \& Management, 40(1), 97-111.

Wonpyo, Y. (2010, Feb. 22). University releases Kindle pilot data. The Daily Princetonian, retrieved Sept. 26, 2010, from http://www.dailyprincetonian.com/2010/02/22/25262/

Young, J. (2010, Apr. 19). Kindle failed tests at several colleges. Will iPads do better? The Chronicle of Higher Education - Wired Campus, Retrieved Sept. 26, 2010, from http://chronicle.com/blogPost/Kindle-Failed-Tests-at-Seve/23253/ 
[Appendix]

Illustrations of students' academic information environments and organization
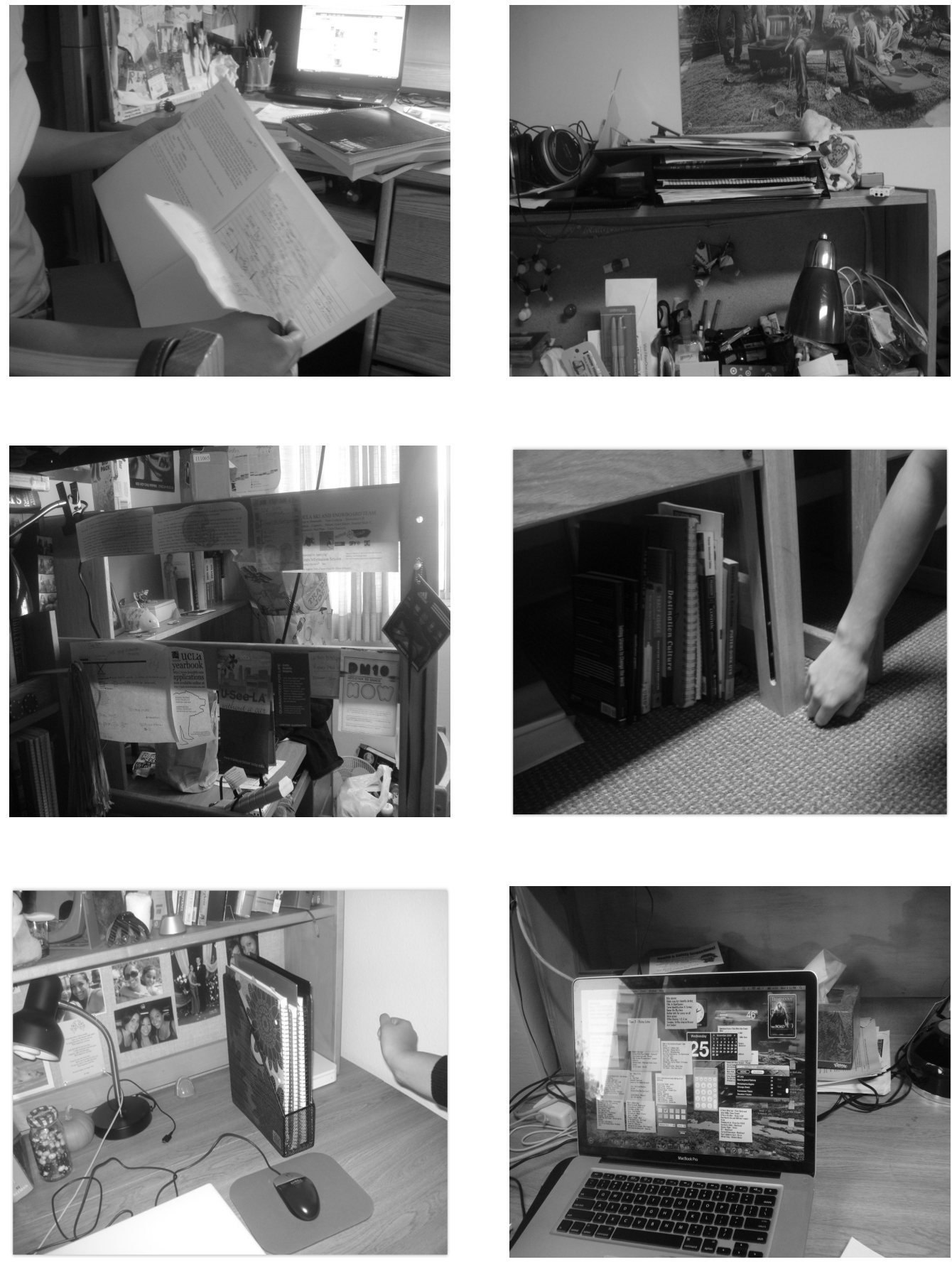